\title{
Metformin and insulin treatment of gestational diabetes: effects on inflammatory markers and IGF-binding protein-1 - secondary analysis of a randomized controlled trial
}

\author{
Mikael S. Huhtala ${ }^{1,2^{*}}$ (D), Kristiina Tertti ${ }^{1,2}$, Juuso Juhila ${ }^{3}$, Timo Sorsa ${ }^{4,5}$ and Tapani Rönnemaa ${ }^{6,7}$
}

\begin{abstract}
Background: Gestational diabetes mellitus (GDM) is characterized by disturbed glucose metabolism and activation of low-grade inflammation. We studied whether metformin treatment has favorable or unfavorable effects on inflammatory markers and insulin-like growth factor-binding protein 1 (IGFBP-1) in GDM patients compared with insulin, and whether these markers associate with major maternal or fetal clinical outcomes.

Methods: This is a secondary analysis of a previous randomized controlled trial comparing metformin $(n=110)$ and insulin $(n=107)$ treatment of GDM. Fasting serum samples were collected at the time of diagnosis (baseline, mean 30 gestational weeks [gw]) and at $36 \mathrm{gw}$. Inflammatory markers serum high-sensitivity CRP (hsCRP), interleukin-6 (IL6), matrix metalloproteinase-8 (MMP-8) and glycoprotein acetylation (GlycA) as well as three IGFBP-1 phosphoisoform concentrations were determined.

Results: In the metformin and insulin groups combined, hsCRP decreased ( $p=0.01)$, whereas IL-6 $(p=0.002)$, GlycA $(p<0.0001)$ and all IGFBP-1 phosphoisoforms $(p<0.0001)$ increased from baseline to $36 \mathrm{gw}$. GlycA $(p=0.02)$ and non-phosphorylated IGFBP-1 $(p=0.008)$ increased more in patients treated with metformin than those treated with insulin. Inflammatory markers did not clearly associate with pregnancy outcomes but non-phosphorylated IGFBP-1 was inversely associated with gestational weight gain.

Conclusions: Metformin had beneficial effects on maternal serum IGFBP-1 concentrations compared to insulin, as increased IGFBP-1 related to lower total and late pregnancy maternal weight gain. GlycA increased more during metformin treatment compared to insulin. The significance of this observation needs to be more profoundly examined in further studies. There were no evident clinically relevant relations between inflammatory markers and pregnancy outcome measures.

(Continued on next page)
\end{abstract}

\footnotetext{
* Correspondence: misahu@utu.fi

'Department of Obstetrics and Gynecology, University of Turku, 20014 Turku,

Finland

2Department of Obstetrics and Gynecology, Turku University Hospital,

Kiinamyllynkatu 4-8, Fl-20521 Turku, Finland

Full list of author information is available at the end of the article
}

C The Author(s). 2020 Open Access This article is licensed under a Creative Commons Attribution 4.0 International License, which permits use, sharing, adaptation, distribution and reproduction in any medium or format, as long as you give appropriate credit to the original author(s) and the source, provide a link to the Creative Commons licence, and indicate if changes were made. The images or other third party material in this article are included in the article's Creative Commons licence, unless indicated otherwise in a credit line to the material. If material is not included in the article's Creative Commons licence and your intended use is not permitted by statutory regulation or exceeds the permitted use, you will need to obtain permission directly from the copyright holder. To view a copy of this licence, visit http://creativecommons.org/licenses/by/4.0/. The Creative Commons Public Domain Dedication waiver (http://creativecommons.org/publicdomain/zero/1.0/) applies to the data made available in this article, unless otherwise stated in a credit line to the data. 
(Continued from previous page)

Trial registration: The trial comparing metformin and insulin treatment was registered in ClinicalTrials.gov (NCT01240785) November 3, 2010. Retrospectively registered.

Keywords: Gestational diabetes, Metformin, Low-grade inflammation, Insulin-like growth factor-binding protein 1, IGFBP-1

\section{Background}

Gestational diabetes mellitus (GDM) is a growing health concern. It is associated with obesity and low-grade inflammation and increases the risk for pregnancy complications, such as macrosomia, preeclampsia, neonatal hypoglycemia and hyperbilirubinemia and the need for neonatal intensive care $[1,2]$. In the long term GDM causes metabolic perturbations - it increases the risk for obesity and metabolic syndrome in the offspring [3] and the risk for type 2 diabetes (T2DM) in the mother [4]. Metformin treatment of GDM reduces gestational weight gain (GWG), gestational hypertension, the incidence of neonatal hypoglycemia and the need for neonatal intensive care compared to insulin treatment [5]. Although the benefits of metformin treatment during the pregnancy have been well characterized, there are concerns regarding the long term effects specially on the offspring [6]. Furthermore we do not know whether metformin has beneficial effects on low-grade inflammation compared to insulin.

Elevated serum IL-6 and high-sensitivity C-reactive protein (hsCRP) are markers of inflammation and predict the onset of T2DM [7]. Dysregulation of inflammation may be involved also in the pathogenesis of GDM [8]: hsCRP $[9,10]$, IL-6 [11] and glycoprotein acetylation (GlycA) [12] are related to GDM, and hsCRP also predicts the persistence of glucose intolerance postpartum [13]. Matrix metalloproteinase 8 (MMP-8), a more recent inflammatory marker, is related to intra-amniotic infection [14] and cervical ripening [15], but MMP-8 activity seems also to be increased in patients with GDM [16].

Besides inflammatory markers, a low serum concentration of insulin-like growth factor-binding protein 1 (IGFBP-1) is associated with GDM and an unfavorable metabolic profile [17]. IGFBP-1, in particular, is thought to play a significant role during pregnancy by regulating plasma glucose levels and being related to fetal growth [18]. Phosphorylation of IGFBP-1 increases its affinity to insulin like growth factor 1 (IGF-1). In the normal state, the highly phosphorylated isoform (high-pIGFBP-1) prevails, but during pregnancy, a non-phosphorylated IGFBP-1 (non-pIGFBP-1) is also detected. In cord blood, both phosphoisoforms are decreased in GDM and inversely associated to birth weight [19].

Based on earlier studies, metformin may have antiinflammatory properties, as demonstrated by suppression of IL-6 (in vitro) [20] and hsCRP [21]. While insulin inhibits IGFBP-1 production [22], metformin appears to increase
IGFBP-1 expression [23]. However, the possible effects of metformin on inflammatory markers in GDM pregnancy have not been studied in sufficiently large patient cohorts to give an unambiguous answer, and its effects on IGFBP-1 in GDM pregnancy have not been studied previously.

The primary aim of this study was to compare the effects of metformin and insulin treatment on the inflammatory markers hsCRP, IL-6, MMP-8, GlycA and three IGFBP-1 phosphoisoforms. The secondary aim was to examine whether variation in these variables at baseline (mean 30 gestational weeks, gw) or at late pregnancy (36 gw) are associated with the maternal and the neonatal outcomes. We hypothesized that metformin has beneficial effects on the inflammatory markers and IGFBP-1 compared to insulin.

\section{Methods}

\section{Study design}

The present study is a secondary analysis of a previous randomized trial [24], in which women with a singleton pregnancy and newly diagnosed GDM were treated either with metformin $(n=110)$ or insulin $(n=107)$ in an open-label randomized design. The original randomized trial was powered to prove non-inferiority of treatment to the primary outcome, which was birth weight. Since this was a secondary analysis, no power-analysis was made to calculate the sample size. However, an additional post-hoc power analysis is included as a supplementary file (Additional file 1). The patients were recruited at the Turku University Hospital on their first visit for management of GDM and they were randomized by the physician using sealed envelopes. GDM diagnosis was made based on the Finnish national guidelines and oral glucose tolerance test (OGTT) thresholds as described before [24]. Metformin treatment was started at a daily dose of $500 \mathrm{mg}$ daily and increased up to 2000 $\mathrm{mg}$ if needed (median $1500 \mathrm{mg}$ ). Additional insulin was given to 23 participants in the metformin group due to unsatisfactory glucose control with metformin only. For insulin treatment, NPH insulin and/or rapid-acting insulin lispro or insulin aspart were used. The trial was approved by the Ethics Committee of the Southwest Hospital District of Finland, the Finnish National Agency of Medicines, and the European Union Drug Regulatory Agency (EUDRA) and registered retrospectively in ClinicalTrials.gov (NCT01240785, http://clinicaltrials.gov/ct2/show/NCT01240785). All participants provided written informed consent. The detailed design 
and outcomes of the randomized trial have been reported elsewhere [24].

For the present analysis Clinical data and serum samples from the previous randomized trial were available from 109 and 107 patients of the metformin and insulin groups, respectively. Those patients in the metformin group who received additional insulin are included in the metformin group unless otherwise specified.

\section{Biochemical methods and clinical variables}

Fasting blood samples were drawn at baseline after the GDM diagnosis had been confirmed (mean 30 [20-34] $\mathrm{gw}$ ) and at $36 \mathrm{gw}$. Serum concentrations of hsCRP and IL6 were measured using ELISA [human C-reactive protein (CRP) ELISA kit, R\&D Systems, Minneapolis, USA; interleukin-6 (IL-6) ELISA kit, R\&D Systems, Minneapolis, USA]. MMP-8, non-pIGFBP-1, low-pIGFBP-1, highpIGFBP-1 were determined using ELISA and an immunoenzymometric assay, as described earlier $[15,25]$, and GlycA according to a high-throughput proton $\left({ }^{1} \mathrm{H}\right)$ nuclear magnetic resonance spectroscopy protocol [26].

Glucose values of the $2 \mathrm{~h} 75 \mathrm{~g}$ OGTT were available at the time of GDM diagnosis. C-peptide, HbA1c, age and pre-pregnancy BMI were assessed as risk factors for GDM and insulin resistance, to examine the relationship with the risk factors, the inflammatory markers and IGFBP-1's. HbA1c was determined using high pressure liquid chromatography and fasting serum C-peptide by an electrochemiluminescence immunoassay. Both analytes were measured at baseline and $\mathrm{HbA} 1 \mathrm{c}$ also at $36 \mathrm{gw}$.

Associations between inflammatory markers, IGFBP-1 phosphoisoforms and the following clinical outcomes were studied, A) maternal outcomes: GWG, preeclampsia or gestational hypertension, gestation length, induction of labor, incidence of cesarean section, and B) fetal outcomes: birth weight, neonate admission to NICU and neonatal intravenous glucose given for any indication. Total GWG was defined as the last measured weight at the maternity clinic minus self-reported weight before pregnancy, and late GWG as the weight gain from the initiation of antihyperglycemic medication. Birth weight was expressed in grams and in SD units (deviation from the mean value of the Finnish general population adjusted for gestation duration [27]). Birth weight $>90$ th percentile was used as an additional indicator of large for gestational age and a birth weight below $<10$ th percentile was used to calculate the incidence of children of small for gestational age.

\section{Statistical analyses}

Categorical clinical data comparison between groups was done with the $\chi^{2}$-test and Fisher's exact test. Comparisons of means or medians was done using the Mann-Whitney $\mathrm{U}$ or t-test, depending on how the data was distributed. Wilcoxon's test or the t-test was used for testing metabolite changes from baseline to $36 \mathrm{gw}$. An ANCOVA analysis was used to adjust for any differences between the compared groups. The normality of distributions was examined using the Shapiro-Wilk test when $n<100$ and Kolmogorov-Smirnov's test with Lilliefors's correction for larger samples sizes. For correlations, Spearman's rank correlation was used. For linear and logistic regression analyses, continuous variables were first centered and scaled, except for birth weight which already was expressed in terms of SD-units. Regression analyses were run both unadjusted and adjusted for treatment (metformin or insulin) and/or pre-pregnancy BMI, which was a priori thought to be the most clinically important confounding factor. Group-specific regression coefficients are given if the pharmacological treatment interacted significantly $(p<0.05)$ with the association between the independent and outcome variable in the regression model. Confidence intervals $(\mathrm{CI})$ for regression coefficients were acquired with the adjusted bootstrap percentile method.

Results are reported with 95\% CI; p $<0.05$ was considered statistically significant. Bonferroni adjustment was applied on the regression analyses. Statistical analyses were run on the $\mathrm{R}$ statistics software (version 3.3.2, http://cran.r-project.org). This study adheres to CONSORT guidelines (http://www.consort-statement.org) for reporting clinical trials.

\section{Results}

The study population characteristics are given in Table 1. Metformin and insulin groups were similar in terms of OGTT values, HbA1c at both time points, C-peptide, age, pre-pregnancy BMI and GWG. There were no differences in birth weight or proportion of primipara. There were no differences between the metformin and insulin groups regarding pregnancy outcomes, except for higher labor induction rates in the insulin group compared to the metformin group ( $54.2 \%$ vs. $37.6 \%, p=0.014)$.

\section{Inflammatory markers and IGFBP-1's at baseline and change from baseline to $36 \mathrm{gw}$}

Comparing metformin and insulin groups at baseline, there were no differences except for marginally lower lowpIGFBP-1 in the metformin group (21.0 vs. 24.0, $p=0.04$ ). Within the metformin group, the inflammatory marker and IGFBP-1 concentrations did not differ when compared to those who required additional insulin treatment. Baseline and $36 \mathrm{gw}$ values of the inflammatory markers and IGFBP-1's are provided in detail in Additional file 2.

Changes in inflammatory markers and IGFBP-1 phosphoisoforms and comparison of changes are shown in Table 2. In the metformin and insulin groups combined, the hsCRP concentration decreased from baseline to $36 \mathrm{gw}$, whereas the IL-6, GlycA and IGFBP-1 concentrations increased. GlycA $(p=0.02)$ and non-pIGFBP-1 $(p=0.008)$ increased more in 
Table 1 Clinical characteristics of the study population

\begin{tabular}{|c|c|c|c|c|c|}
\hline Variable & Metformin & $n$ & Insulin & $n$ & $\boldsymbol{p}$-value \\
\hline \multicolumn{6}{|l|}{ Patients characteristics } \\
\hline Age (years) & $31.9 \pm 5.01$ & 109 & $32.0 \pm 5.47$ & 107 & 0.89 \\
\hline Smoking & $9(8.6)$ & 105 & $17(16.0)$ & 106 & 0.099 \\
\hline Primipara & $42(38.5)$ & 109 & $49(45.8)$ & 107 & 0.28 \\
\hline Pre-pregnancy BMI (kg/m²) & $29.5 \pm 5.91$ & 109 & $28.9 \pm 4.71$ & 107 & 0.41 \\
\hline \multicolumn{6}{|l|}{ Glucose metabolism } \\
\hline $\mathrm{HbA} 1 \mathrm{c} \%$ at OGTT & $5.48 \pm 0.34$ & 109 & $5.51 \pm 0.34$ & 107 & $0.49+$ \\
\hline $\mathrm{HbA} 1 \mathrm{c}$ at OGTT $(\mathrm{mmol} / \mathrm{mol})$ & $36.3 \pm 3.69$ & & $36.7 \pm 3.72$ & & \\
\hline $\mathrm{HbA} 1 \mathrm{c} \%$ at $36 \mathrm{gw}$ & $5.68 \pm 0.33$ & 101 & $5.69 \pm 0.36$ & 95 & 0.82 \\
\hline $\mathrm{HbA} 1 \mathrm{c}$ at $36 \mathrm{gw}(\mathrm{mmol} / \mathrm{mol})$ & $38.5 \pm 3.63$ & & $38.6 \pm 3.89$ & & \\
\hline OGTT fasting (mmol/L) & $5.52 \pm 0.55$ & 109 & $5.57 \pm 0.42$ & 107 & 0.44 \\
\hline OGTT $1 \mathrm{~h}$ (mmol/L) & $11.2 \pm 1.49$ & 109 & $11.2 \pm 1.24$ & 107 & $0.61 \dagger$ \\
\hline OGTT $2 \mathrm{~h}(\mathrm{mmol} / \mathrm{L})$ & $8.33 \pm 1.76$ & 108 & $7.91 \pm 1.75$ & 106 & 0.076 \\
\hline C-peptide at baseline (nmol/L) & $1.05 \pm 0.33$ & 103 & $1.05 \pm 0.29$ & 101 & $0.90 \dagger$ \\
\hline \multicolumn{6}{|l|}{ Pregnancy outcomes } \\
\hline Gestational hypertension & $2(1.8)$ & 109 & $4(3.7)$ & 107 & $0.44 \ddagger$ \\
\hline Preeclampsia & $5(4.6)$ & 109 & $10(9.3)$ & 107 & $0.19 \neq$ \\
\hline Assisted vaginal delivery & $9(8.3)$ & 109 & $8(7.5)$ & 107 & 0.83 \\
\hline Cesarean section & $15(13.8)$ & 109 & $18(16.8)$ & 107 & 0.53 \\
\hline Induction of labor & $41(37.6)$ & 109 & $58(54.2)$ & 107 & 0.014 \\
\hline Gestational weight gain (kg) & $7.97 \pm 5.24$ & 108 & $7.82 \pm 5.27$ & 107 & 0.83 \\
\hline Weight gain in late gestation (kg) & $1.79 \pm 2.62$ & 109 & $2.15 \pm 2.97$ & 107 & 0.35 \\
\hline Gw at delivery & $39.2 \pm 1.40$ & 109 & $39.4 \pm 1.58$ & 107 & 0.43 \\
\hline \multicolumn{6}{|l|}{ Neonatal outcomes } \\
\hline Birth weight (g) & $3610 \pm 490$ & 109 & $3590 \pm 450$ & 107 & 0.78 \\
\hline Birth weight (SD) & $0.17 \pm 1.05$ & 105 & $0.15 \pm 0.96$ & 107 & 0.91 \\
\hline Birth weight (centiles) & $54.8 \pm 28.9$ & 105 & $54.3 \pm 28.9$ & 107 & \\
\hline Macrosomia & $5(4.6)$ & 109 & $1(0.9)$ & 107 & $0.21 \neq$ \\
\hline Birth weight $<10$ th percentile & $12(11.4)$ & 105 & $9(8.4)$ & 107 & 0.46 \\
\hline Birth weight $>90$ th percentile & $15(14.3)$ & 105 & $17(15.9)$ & 107 & 0.74 \\
\hline Admission to NICU & $33(30.1)$ & 108 & $39(36.4)$ & 107 & 0.36 \\
\hline Newborn I.V. glucose & $25(23.1)$ & 108 & $25(23.6)$ & 106 & 0.94 \\
\hline
\end{tabular}

Data is shown as mean $\pm \mathrm{SD}$ or $\mathrm{n}(\%)$. The $p$-value is given for the $\mathrm{t}$-test or the Mann-Whitney $\mathrm{U}$ (indicated with $\dagger$ ) and for categorical data for the $\mathrm{x}^{2}$-test or Fisher's exact test (indicated with $\neq$ ). The number of mothers with clinical variables varied slightly due to missing data for some variables. OGT = oral glucose tolerance test, $\mathrm{gw}=$ gestational weeks, $\mathrm{SD}=$ standard deviation, $\mathrm{NICU}=$ neonatal intensive care unit, I.V. = intravenous. Birth weight in SD and centiles were adjusted for Finnish population growth charts. Macrosomia was defined as birth weight $>4500 \mathrm{~g}$ or $>2$ SD

patients treated with metformin than with insulin but otherwise there were no statistically significant differences in these changes between the groups.

\section{Correlations between inflammatory markers, age, pre-} pregnancy BMI and measures of glucose metabolism Spearman's correlations for inflammatory markers, IGFBP1 's, age and variables related to pre-pregnancy BMI and glucose metabolism among the metformin and insulin treated patients are represented in Fig. 1. At baseline, hsCRP and IL6 correlated positively and IGFBP-1 phosphoisoforms inversely with pre-pregnancy BMI and C-peptide. GlycA correlated at baseline with $\mathrm{HbA} 1 \mathrm{c}$ and $\mathrm{C}$-peptide but not with pre-pregnancy BMI. MMP-8 measured at baseline correlated only weakly with pre-pregnancy BMI.

Regression analyses between inflammatory markers, IGFBP-1's and clinical outcomes in metformin and insulin treated patients

Baseline

Non-pIGFBP-1 at baseline was associated with lesser total and late GWG (Table 3 and Additional file 3). After 
Table 2 Change in concentrations of inflammatory markers and IGFBP-1 phosphoisoforms from baseline to 36 gestational weeks

\begin{tabular}{|c|c|c|c|c|c|c|c|}
\hline \multirow{3}{*}{$\begin{array}{l}\text { Variable } \\
\text { n }\end{array}$} & \multirow{2}{*}{\multicolumn{2}{|c|}{$\begin{array}{l}\text { Metformin and insulin combined } \\
179\end{array}$}} & \multirow{2}{*}{\multicolumn{2}{|c|}{$\begin{array}{l}\text { Metformin } \\
94 \\
\end{array}$}} & \multirow{2}{*}{\multicolumn{2}{|c|}{$\begin{array}{l}\text { Insulin } \\
85 \\
\end{array}$}} & \multirow{3}{*}{$\begin{array}{l}\boldsymbol{p} \text {-value for } \\
\text { comparison } \\
\text { of changes } \\
\text { (metf vs ins) }\end{array}$} \\
\hline & & & & & & & \\
\hline & $\begin{array}{l}\text { median/mean } \\
(95 \% \mathrm{Cl})\end{array}$ & $p$-value & $\begin{array}{l}\text { median/mean } \\
(95 \% \text { Cl) }\end{array}$ & $p$-value & $\begin{array}{l}\text { median/mean } \\
(95 \% \mathrm{Cl})\end{array}$ & $p$-value & \\
\hline \multicolumn{8}{|l|}{ Inflammation } \\
\hline hsCRP (mg/L) & $-0.47[-1.3 ;-0.014]$ & 0.011 & $-0.45[-1.7 ; 0.16]$ & 0.028 & $-0.47[-1.8 ; 0.093]$ & 0.18 & 0.72 \\
\hline IL-6 (ng/L) & $0.70[0.20 ; 1.40]$ & 0.002 & $0.85[0.50 ; 1.8]$ & 0.002 & $0.62[-0.19 ; 1.4]$ & $0.13 \neq$ & 0.31 \\
\hline MMP-8 ( $\mu \mathrm{g} / \mathrm{L})$ & $0.0[-2.0 ; 0.80]$ & 0.50 & $-0.70[-2.0 ; 1.0]$ & 0.76 & $0.70[-2.0 ; 2.6]$ & 0.20 & 0.28 \\
\hline GlycA (mmol/L) & $0.11[0.089 ; 0.13]$ & $<0.0001$ & $0.15[0.11 ; 0.18]$ & $<0.0001 \neq$ & $0.091[0.064 ; 0.12]$ & $<0.0001 \neq$ & 0.020 \\
\hline \multicolumn{8}{|l|}{ IGFBP-1 } \\
\hline Non-phosphorylated ( $\mu \mathrm{g} / \mathrm{L})$ & $17.0[13.0 ; 20.5]$ & $<0.0001$ & $21.0[14.0 ; 26.0]$ & $<0.0001$ & $13.4[7.9 ; 18.9]$ & $<0.0001 \neq$ & 0.008 \\
\hline Low-phosphorylated ( $\mu \mathrm{g} / \mathrm{L})$ & $6.0[4.0 ; 7.9]$ & $<0.0001$ & $6.0[3.6 ; 7.5]$ & $<0.0001$ & $4.0[-2.0 ; 4.0]$ & 0.021 & 0.081 \\
\hline High-phosphorylated ( $\mu \mathrm{g} / \mathrm{L})$ & $300[190 ; 410]$ & $<0.0001 \neq$ & $260[110 ; 420]$ & $0.001 \neq$ & $340[180 ; 500]$ & $<0.0001 \neq$ & $0.48+$ \\
\hline
\end{tabular}

Median/mean change from baseline to 36 gestational weeks [95\% confidence interval (CI)]. Positive values indicate increase and negative values decrease. $p$-values are given for the one-sample t-test (indicated with $¥$ ) or Wilcoxon's signed rank test (comparisons not indicated by $\ddagger$ ). For comparison of changes between metformin and insulin groups, Mann-Whitney's U-test or the t-test (indicated with †) was used. hsCRP = high sensitivity CRP, IL-6 = interleukin 6 , MMP-8 = matrix metalloproteinase 8, GlycA = glycoprotein acetylation, IGFBP-1 = insulin-like growth factor-binding protein 1. $\mathrm{n}$-values for GlycA are 190, 99 and 91 for combined, metformin and insulin groups, respectively

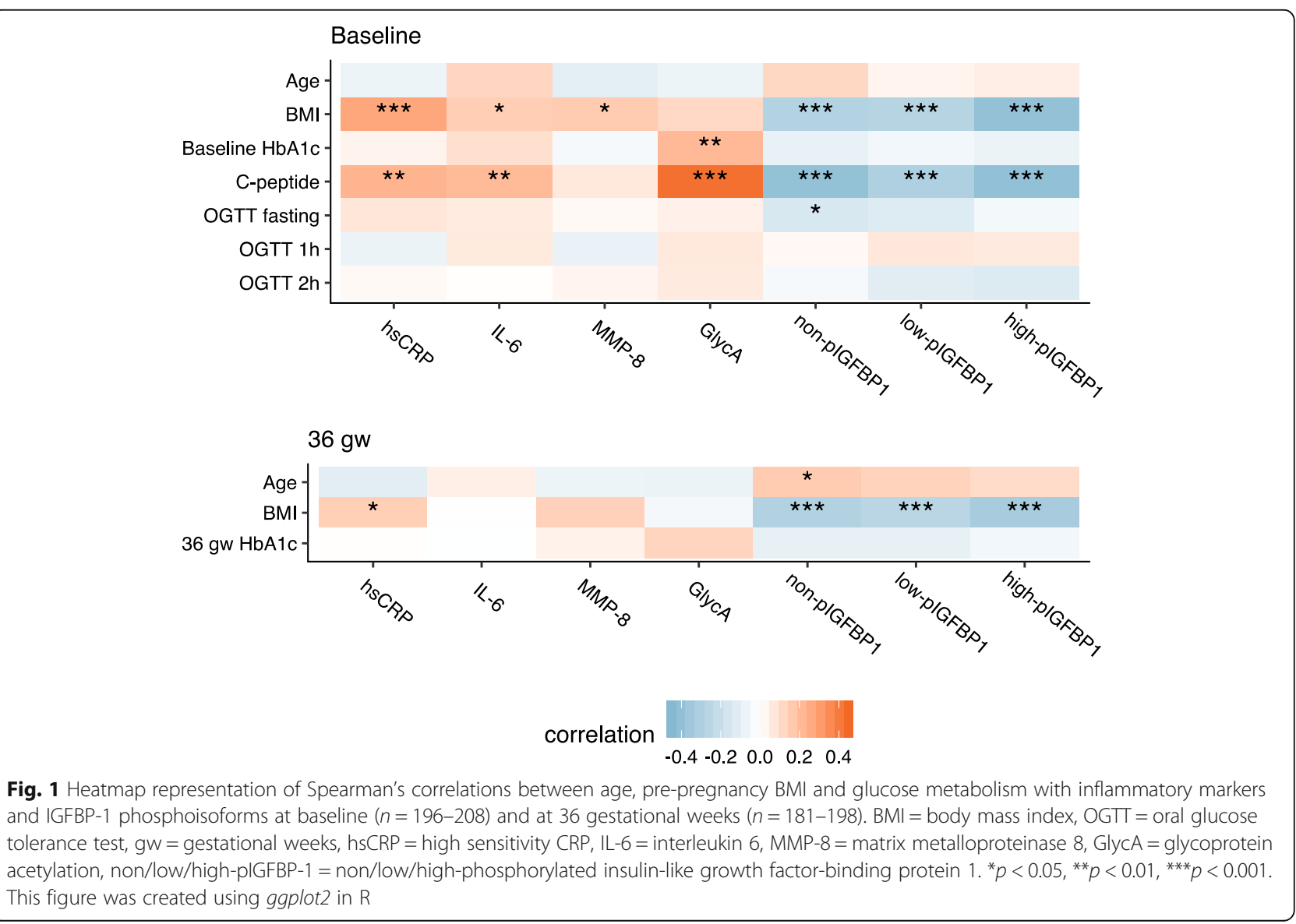


Table 3 Regression models with significant $(p<0.05)$ association of inflammatory markers and IGFBP-1 concentrations with maternal and neonatal outcomes

\begin{tabular}{|c|c|c|c|}
\hline Independent variable & Outcome & $\beta$-estimate [95\% CI] ( $\boldsymbol{p}$-value) & $\mathrm{n}$ total \\
\hline \multicolumn{4}{|l|}{ Baseline } \\
\hline non-plGFBP-1 & total GWG (kg/SD) & $-1.2[-2 ;-0.64](<0.001)^{*}$ & 201 \\
\hline MMP-8 & late GWG (kg/SD) & $0.41[0.022 ; 0.77](0.035)$ & 202 \\
\hline non-plGFBP-1 & late GWG (kg/SD) & $0.45[-0.87 ;-0.13](0.021)$ & 202 \\
\hline hsCRP & length of gestation (weeks/SD) & $0.2[0.028 ; 0.36](0.044)$ & 202 \\
\hline high-plGFBP-1 & induction of labor (OR/SD)† & $0.67[0.48 ; 0.92](0.0094)$ & 202 \\
\hline non-plGFBP-1 & birth weight (SD/SD) & $-0.15[-0.32 ;-0.052](0.027)$ & 198 \\
\hline \multicolumn{4}{|l|}{36 gestational weeks } \\
\hline non-plGFBP-1 & total GWG (kg/SD) & $-1.1[-1.8 ;-0.52](0.0027)^{*}$ & 188 \\
\hline non-plGFBP-1 & late GWG (kg/SD) & $-0.55[-0.96 ;-0.21](0.0069)$ & 189 \\
\hline non-plGFBP-1 & cesarean section $(\mathrm{OR} / \mathrm{SD}) \neq$ & $0.49[0.24 ; 0.84](0.043)$ & 189 \\
\hline MMP-8 & birth weight (SD/SD) & $-0.17[-0.34 ;-0.037](0.022)$ & 185 \\
\hline
\end{tabular}

Both metformin and insulin treated patients were included. Induction of labor was performed in 92 and cesarean section in 26 women. Data is given as regression $\beta$-estimates or odds ratios (OR) in respect to one SD change of the predictor [95\% confidence interval, $\mathrm{Cl}$ ] ( $p$-value). The reference groups for binary outcomes were no induction of labor ( $\dagger$ ) and vaginal delivery ( $¥) . S D=$ standard deviation, GWG = (maternal) gestational weight gain, plGFBP-1 = phosphorylated insulin-like growth factor-binding protein $1, \mathrm{MMP}-8=$ matrix metalloproteinase $8, \mathrm{hsCRP}=$ high sensitivity CRP. ${ }^{*} p<0.0045$ (Bonferroni)

adjustment for pre-pregnancy BMI, both non-pIGFBP-1 $(-1.5 \mathrm{~kg} / \mathrm{SD}, p<0.0001)$ and low-pIGFBP-1 $(-0.99 \mathrm{~kg} / \mathrm{SD}$, $p=0.0037$ ) were inversely associated with total GWG and non-pIGFBP-1 $(-0.47 \mathrm{~kg} / \mathrm{SD}, p=0.019)$ with late GWG (see Additional file 4 for adjusted regression results). Irrespective of these adjustments, MMP-8 was associated with late, but not total GWG. Only after adjustment for prepregnancy BMI, was hsCRP associated with total GWG $(0.72 \mathrm{~kg} / \mathrm{SD}, p=0.05)$. HsCRP was positively associated with the gestation length and was not affected by adjustment for pre-pregnancy BMI $(0.20$ weeks $/ \mathrm{SD}, p=0.048)$. Non-pIGFBP-1 was associated with lower birth weight before $(-0.15$ SD-unists/SD, $p=0.027)$ and after $(-0.14$ SDunits/SD, $p=0.049$ ) adjustment for pre-pregnancy BMI.

\section{Gestational week 36}

Similarly to baseline, non-pIGFBP-1 measured at $36 \mathrm{gw}$ was associated with lesser total and late GWG, and after adjustment for pre-pregnancy BMI also low-pIGFBP-1 was associated with total GWG. In the metformin group, MMP-8 was related to higher late GWG $(0.74 \mathrm{~kg} / \mathrm{SD}$, $p=0.35)$ and hsCRP with longer gestation ( 0.40 weeks/ $\mathrm{SD}, p=0.046)$, and these associations were unaffected by adjustment for pre-pregnancy BMI. A high non-pIGFBP-1 concentration was related to a lower incidence for cesarean section (OR: $0.49, p=0.043$ ), but this association was no longer significant after adjustment for prepregnancy BMI. A high MMP-8 was associated with lower birth weight $(-0.17 \mathrm{SD}$-units/SD, $p=0.022)$, and this association was not affected by pre-pregnancy BMI.

When the regression $p$-values at each time point were adjusted using Bonferroni method, the associations between non-pIGFBP-1 and GWG remained significant at both time points in models irrespective of adjustment for pre-pregnancy BMI. In addition the association between low-pIGFBP-1 at baseline and total GWG was significant in the regression adjusted for pre-pregnancy BMI. Regression results for metformin and insulin groups separately are shown in Additional file 5, for those models in which there was a significant interaction $(p<0.05)$ in the association between the independent and outcome variable. None of the $p$-values for metformin and insulin groups separately reached Bonferroni adjusted threshold of $p<0.0045$.

\section{Discussion}

Seven biomarkers at the time of GDM diagnosis and at 36 gestational weeks were analyzed and the effects of metformin and insulin treatment on the biomarker concentrations and their relation to clinical outcomes were compared. In addition to the traditional markers hsCRP and IL-6, also MMP-8 and GlycA were included in the analyses, since both of these markers are promising markers of cardiovascular risk outside pregnancy [28, 29].

In both treatment groups hsCRP decreased from baseline to $36 \mathrm{gw}$, as demonstrated previously in non-diabetic obese and normal-weight pregnant women [30]. To our knowledge, this is the largest sample comparing the effect of metformin and insulin on hsCRP in GDM. In another large trial comparing metformin and insulin treatment in GDM (the MiG trial), CRP remained unchanged from GDM diagnosis to $36 \mathrm{gw}$ [31]. Notwithstanding the different quantification method, this difference may be explained by lower baseline hsCRP in the MiG study [31]. Conversely, hsCRP has been related to BMI [32], which was higher in MiG than in our cohort; this emphasizes the 
possible effects of ethnicity and the need for absolutely identical diagnostic criteria for GDM.

In line with previous reports in non-diabetic subjects, IL-6 increased during the last trimester of pregnancy [30]. IL-6 is secreted to a large extent by adipocytes and correspondingly higher serum concentrations are associated with higher BMI [30]. However, IL-6 has also antiinflammatory effects [33] and considering the lack of associations with any adverse outcomes in our data, the complexity of IL-6 signaling in pregnancy remains incompletely understood. Still, we have demonstrated that compared with insulin metformin treatment of GDM does not appear to affect serum IL-6.

Previously it has been shown that, in the presence of premature rupture of membranes, maternal serum IL-6 predicts preterm delivery at $72 \mathrm{~h}$ before delivery [34]. In our data there was an inverse, albeit statistically nonsignificant association between IL-6 at $36 \mathrm{gw}$ and gestation length.

Serum GlycA increased in both treatment groups but more in response to metformin treatment. This is in contrast to a previous study in non-diabetic individuals where metformin did not affect serum GlycA [35]. However, the serum concentrations of some glycoproteins, such as $\alpha-1$-acid glycoprotein and $\alpha$-1-antitrypsin, change in normal pregnancy [36], and this confuses the interpretation of GlycA. In general, pregnancy is associated with activation of the innate immune system and with an increase in the concentration of acute phase proteins in the serum. An overall increase of GlycA during pregnancy has been reported previously in a population cohort study [37] and this probably reflects changes in the immune system [38]. High GlycA predicts T2DM [39] and cardiovascular [29] risk in non-pregnant women. Similarly, in pregnancy it has been associated with insulin resistance, a poor lipid profile [40] and GDM in obese women [12]. In agreement with this, GlycA correlated with $\mathrm{HbA1c}$ and C-peptide at baseline but not with HbA1c at $36 \mathrm{gw}$. These results suggest that GlycA may not be a reliable marker of inflammation near term, possibly due to changes in glycoprotein composition [36].

Serum MMP-8 was rather constant during the last trimester of pregnancy, and to our knowledge this is the first longitudinal study characterizing MMP-8 in GDM. Outside GDM, MMP-8 is associated with chorioamnionitis [14] and preterm delivery [41]. Although we did not observe an association between maternal serum MMP-8 and gestation length, MMP-8 was associated with a slightly reduced birth weight. Serum MMP-8 may indicate subclinical inflammation of the placenta or the chorion, which would affect birth weight.

In normal pregnancy, serum IGFBP-1 increases during the first trimester and then decreases slightly before another peak just before delivery [42]. In our data, IGFBP-1 phosphoisoform concentrations increased from baseline to $36 \mathrm{gw}$ in both treatment groups. NonpIGFBP-1 concentrations increased significantly more in women treated with metformin, and there was a trend towards a higher concentration of low-pIGFBP-1. In line with this, metformin causes a marked increase in IGFBP-1 in non-pregnant women with the polycystic ovary syndrome [43]. Metformin increases insulin sensitivity and this might decrease insulin levels. There is a negative feedback loop from insulin to the production of IGFBP-1 [22], and this might explain the difference in serum IGFBP-1 levels between the treatment groups. Another possibility is that the increase in IGFBP-1's in the metformin group is a consequence of dietary changes in response to gastrointestinal symptoms often occurring during metformin use. Previously metformin treatment has been related to lower GWG when compared to either insulin [44] or placebo [45]. And although in our data there were no differences in GWG between the treatment groups, non-pIGFBP-1 and lowpIGFBP-1 were inversely associated with GWG.

Neither at baseline nor at 36 gw was there any apparent association between inflammatory markers, IGFBP1 's and clinical outcomes, with the exception of the inverse association between non-pIGFBP-1, low-pIGFBP-1 and GWG.

IGFBP-1 phosphoisoform concentrations were associated with healthier metabolic profiles, as expected, but high non-pIGFBP-1 and low-pIGFBP-1 were also related to lesser GWG. High pre-pregnancy BMI and high GWG are two major risk factors of excessive fetal growth. In spite of that, IGFBP-1's in our data were not clearly associated with any birth weight variables. This is in contrast with previous results from a population cohort where low IGFBP-1 throughout pregnancy was related with a higher birth weight [46]. The discrepancy may at least in part be explained by the fact that our study population, having GDM and being therefore at risk for fetal macrosomia, were given intensive dietary and lifestyle counselling after the GDM diagnosis to prevent excessive weight gain.

Metformin has been found to reduce the risk of gestational hypertension in comparison to insulin [5] and the risk of preeclampsia when compared to placebo [45]. This effect however was unlikely mediated by reduction of insulin resistance in obese patients [47]. In line with these findings, neither IGFBP-1's nor the inflammatory markers were associated with the risk of hypertensive disorders in our data.

Baseline high-pIGFBP-1 in all patients requiring metformin or insulin and low-pIGFBP-1 in metformintreated patients was associated with a lower risk for induction of labor. This may reflect a better overall 
metabolic health of patients with high serum IGFBP-1 while having a lower overall risk for pregnancy complications (of which induction of labor was the most frequent). The induction rate of labor was marginally higher in patients treated with insulin. This might reflect the physicians' perception that GDM treated with insulin is more severe than GDM without insulin treatment.

In our study, at baseline the inflammatory markers hsCRP, IL-6 and GlycA, and IGFBP-1 phosphoisoforms correlated stronger with fasting C-peptide and prepregnancy BMI than with fasting or postprandial glucose. Hence, inflammatory markers and IGFBP-1 phosphoisoforms seem to indicate obesity related insulin resistance.

We have demonstrated that metformin affects serum GlycA and non-pIGFBP-1 in GDM, and that the associations between these markers and clinical outcomes are similar irrespective of the antihyperglycemic treatment used. Based on this data it is unlikely that metformin, at least when started this late in pregnancy, has any significant impact on the systemic low-grade inflammation that is present in GDM [9-12] or reflects morbidity later in life [13]. Follow-up studies are needed to assess the long term safety of metformin treatment of GDM on children. Further on, it needs to be studied whether possible long term consequences are associated with the changes in serum inflammatory markers or IGFBPs.

\section{Strengths and limitations of the study}

We have included two relatively novel inflammatory markers, MMP-8 and GlycA, and provide longitudinal data of their changes during the last trimester of pregnancy. The study design was a randomized controlled trial - a setting that improves the reliability of results. Even so, there are some limitations to our study.

Our sample size was designed to prove non-inferiority of metformin or insulin in birth weight in the previously published primary randomized trial (24). Thus, although the study population is fairly large, it was underpowered to reveal or exclude all studied associations between inflammation markers and IGFBP-1 s and outcome variables. There may also be confounding factors that slightly affect both maternal and neonatal outcomes, but the statistical power of multiple adjusted regression models to examine each outcome closely is limited. The serum samples in late pregnancy were taken at mean 36 gw of the patients. Since the women delivered at mean $39 \mathrm{gw}$, additional samples taken nearer delivery could have provided important additional information on the effect of metformin and insulin. Our population is representative of mostly Caucasian patients in excellent glycemic control, and these results may not necessarily be generalizable to populations of other ethnicities or with inferior glycemic control. Furthermore the indications for induction, cesarean section and NICU admissions vary between countries making comparisons of these outcomes between various studies difficult. The trial was registered at ClinicalTrials.gov retrospectively.

\section{Conclusions}

Metformin had beneficial effects on maternal serum IGFBP-1 concentrations compared to insulin, possibly due to its favorable effect on insulin resistance. IGFBP-1, the non-phosphorylated isoform in particular, related to lower total and late pregnancy maternal weight gain. Otherwise there were no evident clinically relevant relations between inflammatory markers and pregnancy outcome measures. Compared to insulin metformin caused a similar decrease in serum hsCRP and a similar increase in IL- 6 but a slightly greater rise in GlycA. The significance of GlycA, and of IL-6-CRP-signalling in GDM will need to be more profoundly examined in further studies.

\section{Supplementary information}

Supplementary information accompanies this paper at https://doi.org/10. 1186/s12884-020-03077-6. Additional file 1. Post-hoc power analysis.
Additional file 2: Table S1. Comparison of inflammatory markers and
IGFBP-1's at baseline and at 36 gestational weeks.

Additional file 3: Table S2. Associations of inflammatory markers and IGFBP-1 concentrations with clinical outcomes.

Additional file 4: Table S3. Associations of inflammatory markers and IGFBP-1 concentrations at baseline and 36 gestational weeks with clinical outcomes adjusted for pre-pregnancy BMI in metformin and insulin treated patients combined.

Additional file 5: Table S4. Regression models with significant ( $p<$ 0.05 ) interaction between treatment group (metformin or insulin) and the association between outcome and the independent variable.

\section{Abbreviations}

BMI: Body mass index; Cl: Confidence interval; CRP: C-reactive protein; hsCRP: High-sensitivity C-reactive protein; ELISA: Enzyme-linked

immunosorbent assay; FDR: False discovery rate; GDM: Gestational diabetes mellitus; GlycA: Glycoprotein acetylation; Gw: Gestational weeks;

GWG: Gestational weight gain; HbA1c: glycated hemoglobin; IGF-1: Insulinlike growth factor 1; IGFBP-1: (non-plGFBP-1, low-plGFBP-1, high-plGFBP-1) non-phosphorylated / low-phosphorylated / high-phosphorylated insulin-like growth factor-binding protein 1; IL-6: Interleukin-6; LDL: Low-density lipoprotein; MMP-8: Matrix metalloproteinase-8; NICU: Neonatal intensive care unit; OGTT: Oral glucose tolerance test; SD: Standard deviation; T2DM: Type 2 diabetes mellitus

\section{Acknowledgements}

We thank all midwives and physicians of the Turku University Hospital who participated in the original study and contributed to the collection of the serum samples. We extend our gratitude, of course, also to all the pregnant women who participated in the study.

\section{Authors' contributions}

M.H. analyzed the data and wrote the first draft of the manuscript. K.T. provided clinical data on the metformin and insulin treated patients and serum samples of all patients from a previous study, designed the present study and edited and reviewed the manuscript. J.J. carried out the analyses of hsCRP, IL-6, MMP-8 and IGFBP1's and reviewed and edited the manuscript, T.S. participated in the analysis of MMP-8 and reviewed and edited the manuscript, T.R. designed the study and reviewed and edited the manuscript. All authors have approved the final version of the manuscript. 


\section{Funding}

This study was funded by the Turku University Hospital Foundation, Turku, Finland, the State Funding for University Level Health Research, Helsinki, Finland and the Diabetes Research Foundation, Tampere, Finland and the Southwestern Finland Fund of the Research Foundation for Obstetrics and Gynecology, Finland. The funding sources have not had any involvement in the collection or analysis of the data or interpretation of the results.

\section{Availability of data and materials}

The datasets used and/or analysed during the current study are available from the corresponding author on reasonable request.

\section{Ethics approval and consent to participate}

The trial was approved by the Ethics Committee of the Southwest Hospital District of Finland, the Finnish National Agency of Medicines, and the European Union Drug Regulatory Agency (EUDRA). All participants provided written informed consent.

\section{Consent for publication}

Not applicable.

\section{Competing interests}

T.S. and J.J. are inventors of a diagnostic patent for serum MMP-8 (FI 127416 B / 31.5.2018). M.H., K.T. and T.R. do not have any conflicts of interest.

\section{Author details}

${ }^{1}$ Department of Obstetrics and Gynecology, University of Turku, 20014 Turku, Finland. ${ }^{2}$ Department of Obstetrics and Gynecology, Turku University Hospital, Kiinamyllynkatu 4-8, Fl-20521 Turku, Finland. ${ }^{3}$ Medix Biochemica, Klovinpellontie 3, 02180 Espoo, Finland. ${ }^{4}$ Department of Oral and Maxillofacial Diseases, Head and Neck Center, University of Helsinki and Helsinki University Hospital, P.O. Box 63, 00014 Helsinki, Finland. ${ }^{5}$ Department of Dental Medicine, Karolinska Institute, Box 4064, 14104 Huddinge, Sweden. ${ }^{6}$ Department of Medicine, University of Turku, 20014 Turku, Finland. ${ }^{7}$ Department of Medicine, Turku University Hospital, Kiinamyllynkatu 4-8, 20521 Turku, Finland.

Received: 22 January 2020 Accepted: 24 June 2020

Published online: 11 July 2020

\section{References}

1. HAPO Study Cooperative Research Group, Metzger BE, Lowe LP, Dyer AR, Trimble ER, Chaovarindr U, et al. Hyperglycemia and Adverse Pregnancy Outcomes. N Engl J Med. 2008;358:1991-2002. https://doi.org/10.1056/ NEJMoa0707943.

2. Langer $O$, Yogev $Y$, Most O, Xenakis EMJ. Gestational diabetes: the consequences of not treating. Am J Obstet Gynecol. 2005;192:989-97.

3. Clausen TD, Mathiesen ER, Hansen T, Pedersen O, Jensen DM, Lauenborg J, et al. Overweight and the metabolic syndrome in adult offspring of women with diet-treated gestational diabetes mellitus or type 1 diabetes. J Clin Endocrinol Metab. 2009;94:2464-70. https://doi.org/10.1210/jc.2009-0305.

4. Ben-Haroush A, Yogev Y, Hod M. Epidemiology of gestational diabetes mellitus and its association with type 2 diabetes. Diabet Med. 2004;21:10313. https://doi.org/10.1046/j.1464-5491.2003.00985.x.

5. Butalia S, Gutierrez L, Lodha A, Aitken E, Zakariasen A, Donovan L. Shortand long-term outcomes of metformin compared with insulin alone in pregnancy: a systematic review and meta-analysis. Diabet Med. 2017;34:2736.

6. Rowan JA, Rush EC, Plank LD, Lu J, Obolonkin V, Coat S, et al. Metformin in gestational diabetes: the offspring follow-up (MiG TOFU): body composition and metabolic outcomes at 7-9 years of age. BMJ Open Diabetes Res Care. 2018;6:e000456. https://doi.org/10.1136/bmjdrc-2017-000456.

7. Wang X, Bao W, Liu J, Ouyang Y-Y, Wang D, Rong S, et al. Inflammatory markers and risk of type 2 diabetes: a systematic review and meta-analysis. Diabetes Care. 2013;36:166-75. https://doi.org/10.2337/dc12-0702.

8. Challier JC, Basu S, Bintein T, Minium J, Hotmire K, Catalano PM, et al. Obesity in pregnancy stimulates macrophage accumulation and inflammation in the placenta. Placenta. 2008;29:274-81.

9. Lowe LP, Metzger BE, Lowe WL, Dyer AR, McDade TW, Mclntyre HD. Inflammatory mediators and glucose in pregnancy: results from a subset of the hyperglycemia and adverse pregnancy outcome (HAPO) study. J Clin Endocrinol Metab. 2010;95:5427-34.

10. Wolf M, Sandler L, Hsu K, Vossen-Smirnakis K, Ecker UL, Thadhani R. First-trimester Creactive protein and subsequent gestational diabetes. Diabetes Care. 2003;26:819-24.

11. Morisset AS, Dubé MC, Côté JA, Robitaille J, Weisnagel SJ, Tchernof A. Circulating interleukin- 6 concentrations during and after gestational diabetes mellitus. Acta Obstet Gynecol Scand. 2011;90:524-30.

12. White SL, Pasupathy D, Sattar N, Nelson SM, Lawlor DA, Briley AL, et al. Metabolic profiling of gestational diabetes in obese women during pregnancy. Diabetologia. 2017;60:1903-12.

13. Durnwald CP, Downes K, Leite R, Elovitz M, Parry S. Predicting persistent impaired glucose tolerance in patients with gestational diabetes: the role of high sensitivity CRP and adiponectin. Diabetes Metab Res Rev. 2018;34: e2958. https://doi.org/10.1002/dmrr.2958.

14. Kim SM, Romero R, Park JW, Oh KJ, Jun JK, Yoon BH. The relationship between the intensity of intra-amniotic inflammation and the presence and severity of acute histologic chorioamnionitis in preterm gestation. J Matern Neonatal Med. 2015;28:1500-9.

15. Kruit H, Heikinheimo O, Sorsa T, Juhila J, Paavonen J, Rahkonen L. Cervical biomarkers as predictors of successful induction of labour by Foley catheter. J Obstet Gynaecol (Lahore). 2018;38:927-32. https://doi.org/10.1080/ 01443615.2018.1434763.

16. Akcalı A, Gümüş P, Özçaka Ö, Öztürk-Ceyhan B, Tervahartiala T, Husu H, et al. Proteolytic mediators in gestational diabetes mellitus and gingivitis. J Periodontol. 2017;88:289-97. https://doi.org/10.1902/jop.2016.160158.

17. Lappas M. Insulin-like growth factor-binding protein 1 and 7 concentrations are lower in obese pregnant women, women with gestational diabetes and their fetuses. J Perinatol. 2015;35:32-8. https://doi.org/10.1038/jp.2014.144.

18. Madeleneau D, Buffat C, Mondon F, Grimault H, Rigourd V, Tsatsaris V, et al. Transcriptomic analysis of human placenta in intrauterine growth restriction. Pediatr Res. 2015;77:799-807. https://doi.org/10.1038/pr.2015.40.

19. Loukovaara M, Leinonen $P$, Teramo K, Nurminen $E$, Andersson S, Rutanen EM. Effect of maternal diabetes on phosphorylation of insulin-like growth factor binding protein-1 in cord serum. Diabet Med. 2005;22:434-9. https:// doi.org/10.1111/j.1464-5491.2005.01430.x.

20. Desai N, Roman A, Rochelson B, Gupta M, Xue X, Chatterjee PK, et al. Maternal metformin treatment decreases fetal inflammation in a rat model of obesity and metabolic syndrome. Am J Obstet Gynecol. 2013;209:136.e1136.e9. https://doi.org/10.1016/j.ajog.2013.05.001.

21. Goldberg RB, Temprosa MG, Mather KJ, Orchard TJ, Kitabchi AE, Watson KE. Lifestyle and metformin interventions have a durable effect to lower CRP and tPA levels in the diabetes prevention program except in those who develop diabetes. Diabetes Care. 2014;37:2253-60.

22. Suikkari AM, Koivisto VA, Koistinen R, Seppälä M, Yki-Järvinen H. Doseresponse characteristics for suppression of low molecular weight plasma insulin-like growth factor-binding protein by insulin. J Clin Endocrinol Metab. 1989;68:135-40. https://doi.org/10.1210/jcem-68-1-135.

23. Pawelczyk L, Spaczynski RZ, Banaszewska B, Duleba AJ. Metformin therapy increases insulin-like growth factor binding protein-1 in hyperinsulinemic women with polycystic ovary syndrome. Eur J Obstet Gynecol Reprod Biol. 2004;113:209-13.

24. Tertti K, Ekblad U, Koskinen P, Vahlberg T, Rönnemaa T. Metformin vs. insulin in gestational diabetes. A randomized study characterizing metformin patients needing additional insulin. Diabetes. Obes Metab. 2013;15:246-51.

25. Nuutila $M$, Hiilesmaa $\vee$, Kärkkäinen $T$, Ylikorkala O, Rutanen EM. Phosphorylated isoforms of insulin-like growth factor binding protein-1 in the cervix as a predictor of cervical ripeness. Obstet Gynecol. 1999;94:243-9. https://doi.org/10.1097/00006250-199908000-00017.

26. Soininen $P$, Kangas AJ, Wurtz P, Tukiainen T, Tynkkynen T, Laatikainen R, et al. High-throughput serum NMR metabonomics for cost-effective holistic studies on systemic metabolism. Analyst. 2009;134:1781-5.

27. Pihkala J, Hakala T, Voutilainen P, Raivio K. Characteristic of recent fetal growth curves in Finland. Duodecim. 1989;105:1540-6 http://www.ncbi.nlm nih.gov/pubmed/2680445.

28. Kormi I, Nieminen MT, Havulinna AS, Zeller T, Blankenberg S, Tervahartiala T, et al. Matrix metalloproteinase-8 and tissue inhibitor of matrix metalloproteinase-1 predict incident cardiovascular disease events and all-cause mortality in a population-based cohort. Eur J Prev Cardiol. 2017;24:1136-44.

29. Akinkuolie AO, Buring JE, Ridker PM, Mora S. A novel protein glycan biomarker and future cardiovascular disease events. J Am Heart Assoc. 2014 3:e001221. https://doi.org/10.1161/JAHA.114.001221. 
30. Christian LM, Porter K. Longitudinal changes in serum proinflammatory markers across pregnancy and postpartum: effects of maternal body mass index. Cytokine. 2014;70:134-40. https://doi.org/10.1016/j.cyto.2014.06.018.

31. Barrett HL, Gatford KL, Houda CM, De Blasio MJ, Mclntyre HD, Callaway LK, et al. Maternal and neonatal circulating markers of metabolic and cardiovascular risk in the metformin in gestational diabetes (MiG) trial: responses to maternal metformin versus insulin treatment. Diabetes Care. 2013;36:529-36. https://doi.org/10.2337/dc12-1097.

32. Kuzmicki M, Telejko B, Zonenberg A, Szamatowicz J, Kretowski A, Nikolajuk $A$, et al. Circulating pro- and anti-inflammatory cytokines in polish women with gestational diabetes. Horm Metab Res. 2008;40:556-60.

33. Matthews VB, Allen TL, Risis S, Chan MHS, Henstridge DC, Watson N, et al. Interleukin-6-deficient mice develop hepatic inflammation and systemic insulin resistance. Diabetologia. 2010;53:2431-41.

34. Murtha AP, Sinclair T, Hauser ER, Swamy GK, Herbert WNP, Heine RP. Maternal serum cytokines in preterm premature rupture of membranes. Obstet Gynecol. 2007;109:121-7. https://doi.org/10.1097/01.AOG. 0000250474.35369.12.

35. Eppinga RN, Kofink D, Dullaart RPF, Dalmeijer GW, Lipsic E, van Veldhuisen DJ, et al. Effect of metformin on metabolites and relation with myocardial infarct size and left ventricular ejection fraction after myocardial infarction. Circ Cardiovasc Genet. 2017;10:e001564. https://doi.org/10.1161/ CIRCGENETICS.116.001564.

36. Larsson A, Palm M, Hansson LO, Basu S, Axelsson O. Reference values for a1acid glycoprotein, a1-antitrypsin, albumin, haptoglobin, C-reactive protein, IgA, IgG and IgM during pregnancy. Acta Obstet Gynecol Scand. 2008:87:1084-8.

37. Wang $Q$, Würtz $P$, Auro K, Mäkinen V-P, Kangas AJ, Soininen P, et al. Metabolic profiling of pregnancy: cross-sectional and longitudinal evidence. BMC Med. 2016;14:205. https://doi.org/10.1186/s12916-016-0733-0.

38. Ritchie SC, Würtz P, Nath AP, Abraham G, Havulinna AS, Fearnley LG, et al. The biomarker GlycA is associated with chronic inflammation and predicts long-term risk of severe infection. Cell Syst. 2015;1:293-301. https://doi.org/ 10.1016/j.cels.2015.09.007.

39. Akinkuolie AO, Pradhan AD, Buring JE, Ridker PM, Mora S. Novel protein glycan side-chain biomarker and risk of incident type 2 diabetes mellitus. Arterioscler Thromb Vasc Biol. 2015;35:1544-50. https://doi.org/10.1161/ ATVBAHA.115.305635.

40. Mokkala K, Pellonperä O, Röytiö H, Pussinen P, Rönnemaa T, Laitinen K. Increased intestinal permeability, measured by serum zonulin, is associated with metabolic risk markers in overweight pregnant women. Metabolism. 2017;69:43-50. https://doi.org/10.1016/..metabol.2016.12.015.

41. Ashford K, Chavan NR, Wiggins AT, Sayre MM, McCubbin A, Critchfield AS, et al. Comparison of serum and cervical cytokine levels throughout pregnancy between preterm and term births. AJP Rep. 2018;8:e113-20. https://doi.org/10.1055/s-0038-1656534.

42. Larsson A, Palm M, Basu S, Axelsson O. Insulin-like growth factor binding protein-1 (IGFBP-1) during normal pregnancy. Gynecol Endocrinol. 2013;29: 129-32. https://doi.org/10.3109/09513590.2012.730574.

43. Jakubowicz DJ, Seppälä M, Jakubowicz S, Rodriguez-Armas O, RivasSantiago A, Koistinen $\mathrm{H}$, et al. Insulin reduction with metformin increases luteal phase serum glycodelin and insulin-like growth factor-binding protein 1 concentrations and enhances uterine vascularity and blood flow in the polycystic ovary syndrome. J Clin Endocrinol Metab. 2001;86:1126-33.

44. Rowan JA, Hague WM, Gao W, Battin MR, Moore MP. Metformin versus insulin for the treatment of gestational diabetes. N Engl J Med. 2008;358: 2003-15. https://doi.org/10.1056/NEJMoa0707193.

45. Syngelaki A, Nicolaides KH, Balani J, Hyer S, Akolekar R, Kotecha R, et al. Metformin versus placebo in obese pregnant women without diabetes mellitus. N Engl J Med. 2016;374:434-43. https://doi.org/10.1056/ NEJMoa1509819.

46. Åsvold BO, Eskild A, Jenum PA, Vatten LJ. Maternal concentrations of insulin-like growth factor I and insulin-like growth factor binding protein 1 during pregnancy and birth weight of offspring. Am J Epidemiol. 2011;174: 129-35. https://doi.org/10.1093/aje/kwr067.

47. Balani J, Hyer S, Syngelaki A, Akolekar R, Nicolaides KH, Johnson A, et al. Association between insulin resistance and preeclampsia in obese nondiabetic women receiving metformin. Obstet Med. 2017;10:170-3.

\section{Publisher's Note}

Springer Nature remains neutral with regard to jurisdictional claims in published maps and institutional affiliations.

\section{Ready to submit your research? Choose BMC and benefit from}

- fast, convenient online submission

- thorough peer review by experienced researchers in your field

- rapid publication on acceptance

- support for research data, including large and complex data types

- gold Open Access which fosters wider collaboration and increased citations

- maximum visibility for your research: over $100 \mathrm{M}$ website views per year

At BMC, research is always in progress.

Learn more biomedcentral.com/submissions 